\title{
A POU Homeo Domain Protein Related to dPOU-19/pdm-1 Binds to the Regulatory DNA Necessary for Vital Expression of the Drosophila Choline Acetyltransferase Gene
}

\author{
Toshihiro Kitamoto and Paul M. Salvaterra \\ Division of Neurosciences, Beckman Research Institute of the City of Hope, Duarte, California 91010
}

\begin{abstract}
Expression of the choline acetyltransferase (ChAT) gene in Drosophila melanogaster is responsible for production of the neurotransmitter acetylcholine and is necessary for viability. In previous studies, we have shown that the regulatory region for normal ChAT expression is large and composed of multiple regulatory elements (Kitamoto et al., 1992; Kitamoto and Salvaterra, 1993). In this study, using various lengths of 5 ' flanking DNA fused to wild type ChAT cDNA, we have defined a 0.3 kilobase $(\mathrm{kb})$ region of the cis-regulatory DNA, which is essential for restoring viability of Cha lethal mutants. DNase I footprinting analysis of this $0.3 \mathrm{~kb}$ DNA revealed a protected $22 \mathrm{bp}$ sequence that contains an octamer-like motif (ATTCAAAT) with one base difference from the consensus octamer motif (ATGCAAAT). Electrophoretic mobility shift assays and Southwestern blot analysis confirmed the presence of specific binding factor(s) for the 22 bp sequence in embryo nuclear extracts, and competition studies established the importance of the octamer-like motif for high-affinity binding. Using the 22-mer as a probe, we have isolated a cDNA clone encoding the Drosophila POU homeo domain protein, dPOU19/pdm-1, whose target genes and specific binding sequences have not been identified. We propose that vital expression of the Drosophila ChAT gene is regulated by a member of the dPOU-19/pdm-1 putative transcription factor family.
\end{abstract}

[Key words: choline acetyltransferase, neurotransmitter, Drosophila melanogaster, transgenic animal, transcriptional regulation, POU homeo domain gene]

The nervous system is an organized collection of neurons exhibiting cell-specific neurotransmitter phenotypes. Specification and maintenance of these neuronal properties requires restricted expression of a particular set of genes in distinct spatial and temporal patterns. Genetic analysis in Drosophila melanogaster has led to the identification of a large number of genes involved in nervous system development. These include the early acting genes involved in the formation of neuronal progenitor cells and the later acting genes controlling identities of neuronal progenitor cells and their progeny (Campos-Ortega and Jan, 1991;

\footnotetext{
Received July 28, 1994; revised Oct. 12, 1994; accepted Nov. 17, 1994.

We thank Dr. S. Germaraad and Dr. R. Whitson for critically reading the manuscript. This work was supported by a grant from NIH-NINDS.

Correspondence should be addressed to Paul M. Salvaterra, Division of Neuroscience, Beckman Research, Institute of the City of Hope, 1450 Easi Duarte Road, Duarte, CA 91010.

Copyright (c) 1995 Society for Neuroscience $0270-6474 / 95 / 153509-10 \$ 05.00 / 0$
}

Goodman and Doe, 1993; Jan and Jan, 1993). Much less is known about the regulation of genes that specify the terminal stages of nervous system development, when cells actually acquire particular neuronal properties, such as neurotransmitter phenotypes.

The choline acetyltransferase (ChAT; acetylCoA:choline- $O$ acetyltransferase, EC 2.3.1.6) gene encodes the biosynthetic enzyme responsible for production of the neurotransmitter acetylcholine. Expression of ChAT specifies which neurons will have a cholinergic neurotransmitter phenotype. A number of conditional and nonconditional mutations of the Drosophila ChAT gene (Cha) have been generated, and the essential nature of cholinergic transmission for the animal's viability is indicated by the lethality of presumptive null alleles (Greenspan, 1980; Lindsley and Zimm, 1992). Two different temperature-sensitive alleles also result in adult paralysis as well as adult and embryonic lethality when animals are challenged at a restrictive temperature (Greenspan, 1980; Gorczyca and Hall, 1984).

Our previous studies have established that the $5^{\prime}$ flanking DNA of the Drosophila ChAT gene contains multiple regulatory elements that are responsible for ChAT expression in different subsets of cholinergic neurons (Kitamoto et al., 1992; Kitamoto and Salvaterra, 1993). This type of regulation by the combined action of separable elements is also observed for other neuronsubset specific genes in Drosophila, such as the Dopa decarboxylase (Johnson et al., 1989), sevenless (Botwell et al., 1991), and the FMRF amide genes (Schneider et al., 1993). We have also shown that transgenic ChAT expression directed by the proximal $1.2 \mathrm{~kb}$ of $5^{\prime}$ flanking DNA results in rescue of lethality for the Cha mutants, indicating that the more distal regulatory elements are not essential for survival (Kitamoto and Salvaterra, 1993).

In the present study, we have more precisely defined the cisregulatory DNA in the 5 ' flanking region of the ChAT gene that can effect rescue of the lethal Cha mutant phenotype. We found that the proximal $0.8 \mathrm{~kb}$ DNA fragment, when fused to wildtype ChAT cDNA, is sufficient to rescue Cha mutant phenotypes while a $0.5 \mathrm{~kb}$ fragment is not. The distal $0.3 \mathrm{~kb}$ of the $0.8 \mathrm{~kb}$ fragment should thus contain critical regulatory sequence(s) allowing ChAT expression in cholinergic neuronal populations necessary for survival. We have identified a 22 bp putative transcription factor binding site within the critical $0.3 \mathrm{~kb}$, which contains an octamer-like motif and specifically interacts with a Drosophila POU domain protein encoded by the previously described dPOU-19/pdm-l gene (Billin et al., 1991; Dick et al., 1991; Lloyd and Sakonju, 1991). We propose that dPOU- 
19/pdm-1 may thus be an important regulatory factor responsible for vital expression of the Drosophila ChAT gene.

\section{Materials and Methods}

\section{Drosophila stocks and transformants}

Flies were reared under standard conditions on a diet of cornmeal. Stocks containing the conditional $\left(C h a^{t s 1}\right)$ and nonconditional $\left(C h a^{\prime \prime}\right.$ and $\left.C h a^{\prime 13}\right)$ mutant alleles of the ChAT gene were obtained from Dr. Jeff Hall (Brandeis University, Waltham, MA). Chatst was isolated and described by Greenspan (1980). $C h a^{\prime \prime}$ and $C h a^{\prime \prime 3}$ were isolated by Hall et al. (1979) and by L. Myers and W. Gelbart (unpublished), respectively. Both are described in Lindsley and Zimm (1992). Most of transformed lines were generated in Kitamoto et al. (1992) using P-element transformation as outlined in Rubin and Spradling (1982). The $0.8 \mathrm{~kb}-$ and $0.5 \mathrm{~kb}$-ChAT transformants were generated in this study. The $0.8 \mathrm{~kb}$ fragment was obtained by deleting the $5^{\prime}$ portion of the $1.2 \mathrm{~kb}$ fragment using Bluescript ExoIII/Mung DNA sequencing system (Stratagene, La Jolla, CA), and the $0.5 \mathrm{~kb}$ fragment was first subcloned into pBluescribe (Stratagene) as a SacI/BamHI fragment. Each insert was excised as an EcoRI/BamHI fragment and inserted into the polylinker site of pCaSperAUG- $\beta$-gal (Thummel et al., 1988). The lac $Z$ portion of these constructs was replaced by the $2.4 \mathrm{~kb}$ Drosophila ChAT cDNA (Itoh et al., 1986). The appropriately marked and balanced stocks used to test the ability of wild type ChAT cDNA transgenes to rescue lethality were obtained from Rodney Williamson (Beckman Research Institute of the City of Hope, Duarte, CA).

\section{Rescue of Cha mutant phenotypes}

Adult paralysis and embryonic lethality of $\mathrm{Cha}^{\mathrm{s} \mid}$ : for rescue of adult paralysis, 20 flies homozygous for $C h a^{\prime: 1}$ and carrying one copy of a transgene were raised at a restrictive temperature of $30^{\circ} \mathrm{C}$. The number of standing flies was counted after $4 \mathrm{~d}$. Under this condition all $C h a^{\prime s}$ flies are paralyzed and lying on their backs or sides, while the wildtype flies are still fully active. For rescue of $C h a^{t .1}$ embryonic lethality, male ChAT cDNA transformants carrying one copy of a transgene were crossed with $w ; C h a^{i s l}$ females. They were kept at a permissive temperature $\left(22^{\circ} \mathrm{C}\right)$ for $2 \mathrm{~d}$, then transferred to new vials and allowed to lay eggs at a restrictive temperature $\left(30^{\circ} \mathrm{C}\right)$. After $2 \mathrm{~d}, \mathrm{FO}$ flies were removed and all newly eclosed flies developing under the restrictive temperature were scored.

Lethality of nonconditional Cha mutants. The ability of the ChAT cDNA construct to rescue the late embryonic lethality of nonconditional Cha mutants was examined by scoring eclosed adults in the progeny of the following crosses: P[ChAT]/y; Cha $a^{11} / \mathrm{MKRS} \times C h a^{113} / \mathrm{MKRS}$ (for the $\mathrm{X}$ chromosome integration) or $\mathrm{P}[\mathrm{ChAT}] \mathrm{P}[\mathrm{ChAT}]$; $\mathrm{Cha} / \mathrm{TM} 6 \times$ $C h a^{\prime 13} / \mathrm{MKRS}$ (for the second chromosome integration). P[ChAT] indicates either the $\mathrm{X}$ chromosome or the second chromosome carrying a transgenic wild-type ChAT cDNA construct. These crosses yield animals carrying one copy of a transgene and are heterozygous for two noncomplementing Cha mutations ( $C h a^{i 1}$ and $C h a^{13}$ ). For the $0.8 \mathrm{~kb}$ ChAT construct, the following cross was carried out to yield animals carrying two copies of a transgene: P[ChAT]/P[ChAT];Cha $/ 1 / \mathrm{TM}^{\prime} \times$ $\mathrm{P}[\mathrm{ChAT}] / \mathrm{P}[\mathrm{ChAT}] ; C h a^{\prime \prime 3} / \mathrm{TM} 6$.

\section{Measurement of ChAT activity}

ChAT activity was assayed as described previously (Kitamoto et al., 1992). Before measuring the ChAT activity, homogenates were incubated at $37^{\circ} \mathrm{C}$ for $30 \mathrm{~min}$ to inactivate the endogenous temperaturesensitive enzyme (Greenspan, 1980; Salvaterra and McCaman, 1985).

\section{DNase I footprint analysis}

DNase I footprinting analysis was performed according to the method described by Heberlein (1990, in "Rubin's lab methods book," pp 104105 ). The $316 \mathrm{bp}$ fragment extending from $-414 \mathrm{bp}$ to $-99 \mathrm{bp}$, relative to the transcription start site, was labeled with ${ }^{32} \mathrm{P}$ at position $-99 \mathrm{bp}$ and mixed with nuclear extracts that were prepared from 10-22 hr embryos and fractionated on heparin-agarose (Heberlein and Tjian, 1988).

\section{Electrophoretic mobility shift assay}

The double-stranded 22-mer (AGATTCTTATTCAAATGTGCTC) corresponding to the DNase I-protected sequence was end labeled with ${ }^{32} \mathrm{P}$, and the electrophoretic mobility shift assay was carried out with em- bryonic nuclear extracts derived from 10-22 hr embryos. Binding reactions $(10 \mu \mathrm{l})$ were done by incubating the radiolabeled 22 -mer with nuclear extract in binding buffer $(50 \mathrm{mM} \mathrm{NaCl}, 10 \mathrm{~mm}$ Tris- $\mathrm{HCl}, \mathrm{pH}$ $7.5,1 \mathrm{~mm}$ DTT, $1 \mathrm{~mm}$ EDTA, $5 \%$ glycerol) in the presence of $10 \mathrm{~mm}$ $\mathrm{MgCl}_{2}$ and $0.2 \mu \mathrm{g} / \mu \mathrm{l}$ poly (dI-dC). After incubation in the presence or absence of competitor oligonucleotides for $30 \mathrm{~min}$ at room temperature, sample were electrophoresed at $4^{\circ} \mathrm{C}$ on a $5 \%$ polyacrylanide gel with the Tris-glycine high-ionic-strength system (Choosh, 1988), followed by autoradiography. Sequences of oligonucleotides used as a competitor are shown in Figure $5 \mathrm{~A}$. The control oligonucleotide is a double-stranded BamHI/EcoRI adapter purchased from Boehringer-Mannheim (Indianapolis, IN).

\section{Southwestern blot analysis}

Protein samples were separated on a SDS-polyacrylamide gel and transferred to a nitrocellulose membrane. The membrane was treated with 6 $\mathrm{M}$ and then decreasing concentrations of guanidine $\mathrm{HCl}$ at $4^{\circ} \mathrm{C}$ to allow the proteins to refold into a conformationally active form (Sambrook et al., 1989). The double-stranded 22-mer was concatenated, ${ }^{32} \mathrm{P}$ labeled with nick translation, and used to detect specific binding protein on the membrane according to the method described by Sambrook et al. (1989).

\section{Construction and screening of an embryonic cDNA expression library}

Total cellular RNA was prepared from 10-22 hr embryos by the $\mathrm{CsCl}$ /guanadinium isothiocyanate method (Chirgwin et al., 1979). The mRNA was isolated with oligotex-dT suspension (Qiagen, Chatworth, CA) according to the company's protocol. The cDNA expression library was constructed using the ZAP-cDNA synthesis kit (Stratagene) according to the company's protocol. Screening of sequence specific binding factors was performed with the radiolabeled concatenated 22-mer, as described in Sambrook et al. (1989). DNA sequencing was carried out by the dideoxy chain-termination method (Sanger et al., 1977).

\section{Results}

Deletion analysis defines a $0.3 \mathrm{~kb}$ regulatory region necessary to rescue Cha mutants from paralysis and lethality

One aim of the present study was to identify the minimum amount of regulatory DNA that is necessary to direct enough wild-type ChAT expression in appropriate neurons to effect rescue of phenotypes in animals with a Cha mutant genetic background. Figure 1 shows a schematic drawing of the fusion constructs examined for their ability to rescue conditional and nonconditional Cha mutants from paralysis and lethality. They are composed of different amounts of $5^{\prime}$ flanking DNA fused to wild-type ChAT cDNA (Itoh et al., 1986). All constructs except one $(0 \mathrm{~kb}$ ChAT $)$ also contain the transcription start site and 391 bp of $5^{\prime}$ untranslated region from the first exon of the ChAT gene (hatched box in Fig. 1). They are introduced into mutant animals by P-element transformation and standard genetic crosses.

Adult $C h a^{s 1}$ flies are paralyzed and subsequently die at a restrictive temperature because of the inability of the thermolabile $C h a^{\prime s 1}$ enzyme to synthesize sufficient $\mathrm{ACh}$ at a high temperature (Greenspan, 1980). Twenty female transformants, homozygous for $C h a^{\text {s. }}$ and carrying one copy of a particular transgene, were placed in a vial and challenged at a restrictive temperature of $30^{\circ} \mathrm{C}$.

After $4 \mathrm{~d}$ of incubation, standing flies were observed for all of the independently transformed lines carrying the $0.8 \mathrm{~kb}$ construct or for constructs with more distal 5 ' flanking DNA (Fig. 2A). All $C h a^{t s l}$ flies lacking a transgene were paralyzed and lying on their backs or sides under the same conditions (data not shown). Likewise, all animals transformed without regulatory DNA and 14 of 16 lines transformed with the $0.5 \mathrm{~kb}$ construct were paralyzed. These results indicate that the $0.8 \mathrm{~kb}$ DNA frag- 


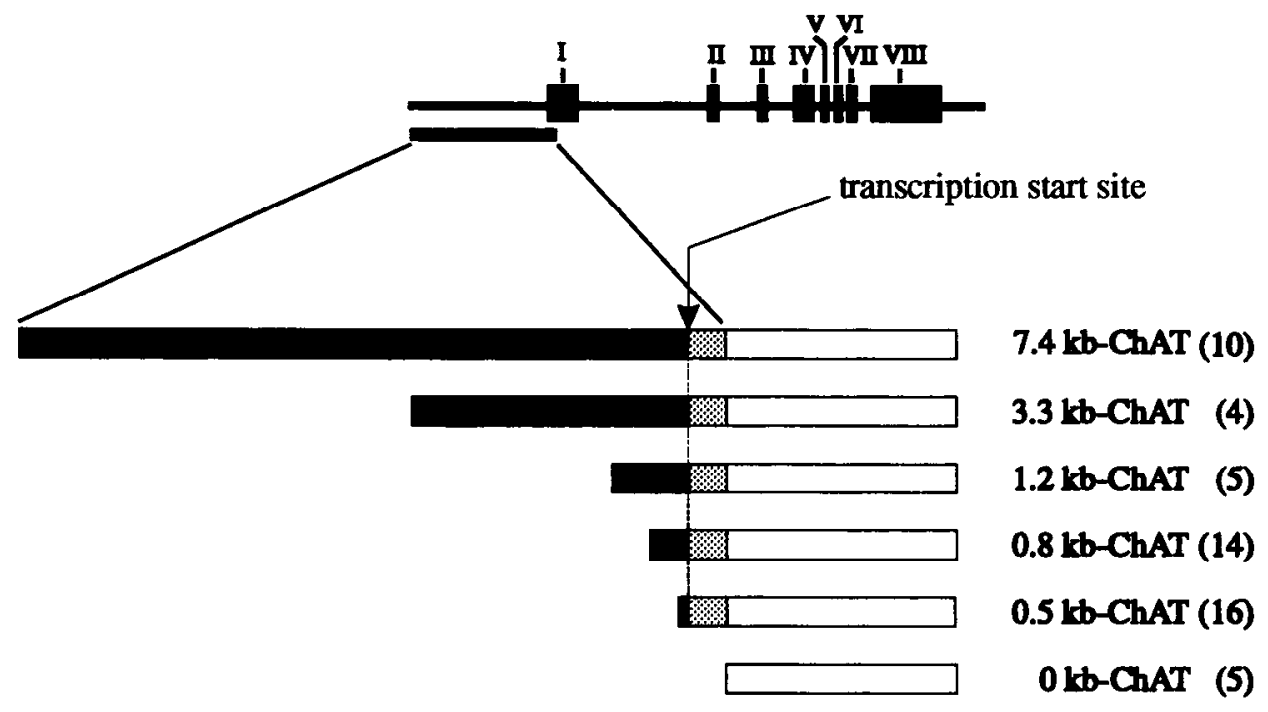

Figure 1. Schematic diagram of ChAT cDNA constructs. At the top is the organization of the Drosophila ChAT gene (Sugihara et al., 1991). The gene consists of cight cxons indicated by solid boxes. The bottom of the figure shows the constructs tested in this study. They are composed of different amounts of 5 ' flanking sequences (solid box), 5' untranslated region (hatched $b o x$ ) and wild-type ChAT cDNA (open $b o x)$. These constructs were introduced into the fly genome by P-element mediated transformation. The number of independent lines for each construct is indicated in parentheses. The transcription and translation start sites are located 391 bp upstream and 19 bp downstream of the $5^{\prime}$ end of the cDNA clone, respectively. ment is sufficient to direct enough ChAT activity in appropriate neurons to rescue temperature-induced paralysis in adult flies with a $C h a^{t s 1}$ mutant background, while the $0.5 \mathrm{~kb}$ fragment is not (in most cases). Thus, the deletion of $0.3 \mathrm{~kb}$ of DNA from the distal end of the $0.8 \mathrm{~kb}$ fragment dramatically affected the ability of adult flies to be rescued from temperature-induced paralysis.

Animals carrying the $C h a^{t s 1}$ allele also exhibit temperaturedependent late embryonic lethality when challenged at $30^{\circ} \mathrm{C}$ from the beginning of development (Greenspan, 1980). As shown in Figure $2 B, 32$ out of 33 independently transformed lines carrying $0.8 \mathrm{~kb}$ or more of flanking sequence yielded adult progeny. For the lines made with the $0.5 \mathrm{~kb}$ fragment, 14 out of 16 failed to yield any eclosed flies, suggesting that the $0.5 \mathrm{~kb}$ DNA fragment is lacking important regulatory elements necessary for ChAT gene expression. These results indicate that the distal $0.3 \mathrm{~kb}$ of the $0.8 \mathrm{~kb}$ DNA contains regulatory sequences necessary to direct sufficient ChAT expression to rescue $C h a^{t s 1}$ embryos from lethality and yield adult flies.

Although most of the $0.5 \mathrm{~kb}$ lines did not show rescue of the adult paralytic or embryonic lethal phenotypes, the same two lines were rescued in both tests. One explanation for this could be the possibility that the $0.5 \mathrm{~kb}$ fragment contains the necessary regulatory elements to direct ChAT expression in appropriate neurons, but lacks sufficient enhancer activity to allow an adequate amount of enzyme to effect rescue. If this were the case, then the two rescued $0.5 \mathrm{~kb}$ lines should exhibit higher transgenic ChAT activity than the other lines which were not rescued. Figure 3 shows the transgenic ChAT activity for each of the transformed lines. Prior to ChAT activity measurement, homogenates were preincubated at a temperature that will inactivate the temperature-sensitive ChAT activity contributed by the endogenous $C h a^{t s}$ allele (Greenspan, 1980; Salvaterra and McCaman, 1985). Most of the $0.5 \mathrm{~kb}$ lines show ChAT activity comparable to that seen in the two rescued $0.5 \mathrm{~kb}$ lines (arrows in Fig. 3). In fact, many of the unrescued $0.5 \mathrm{~kb}$ lines showed ChAT activity that was comparable to that seen in the rescued $0.8 \mathrm{~kb}$ lines. These results indicate that the $0.5 \mathrm{~kb}$ fragment, while conserving the ability to direct a small amount of ChAT expression, does not contain enough regulatory information to direct expression in a biologically useful manner. The $0.5 \mathrm{~kb}$ fragment may, thus, contain sequences necessary for binding of the basic transcriptional machinery such as a TFIID/RNA polymerase complex, but lack sufficient regulatory information for directing ChAT expression in particular neurons necessary for phenotypic rescue. In the two $0.5 \mathrm{~kb}$ lines that were phenotypically rescued, the fusion construct may have "trapped" an enhancer that fortuitously directs transgenic ChAT expression in proper neurons.

We have also examined the ability of the $0.8 \mathrm{~kb}$ construct to rescue lethality of nonconditional Cha mutants by scoring the adult progeny of the genetic crosses described in Materials and Methods. The crosses produced animals that had one or two copies of a transgene and were heterozygous for two noncomplementing, nonconditional $C h a$ lethal mutations, $C h a^{l 1}$ and Cha ${ }^{1 / 3}$ (Lindsley and Zimm, 1992). These mutations are both presumptive null alleles, and all embryos carrying a Cha ${ }^{11} / \mathrm{Cha}^{113}$ genotype die before hatching. If the transgene can completely effect rescue of the Cha mutations from lethality, the percentage of flies with a $C h a^{\prime \prime} / C h a^{113}$ genotype is expected to be $20 \%, 25 \%$, or $33 \%$ for the transformants linked with the X, II (one copy), and II (two copies) chromosomes, respectively. When one dose of the $0.8 \mathrm{~kb}$ construct was introduced into animals with a $C h a^{\prime 1} / C h a^{113}$ background, eclosed adult flies were observed in only one of the four $0.8 \mathrm{~kb}$ lines tested $(0.8 \mathrm{~kb}$ ChAT line 6 , Table 1). The percentage of $C h a^{\prime 1} / C h a^{113}$ adults for that line was only about $10 \%$, less than the $25 \%$ expected. It should be mentioned, however, that many individuals of this cross developed up to the pupal stage (in contrast to late embryonic lethality for animals without a transgene) and died just before eclosion and were, thus, not scored as rescued. One dose of the $0.8 \mathrm{~kb}$ transgene, therefore, seems to be quantitatively insufficient to completely restore $C h a^{\prime 1} / C h a^{\prime 13}$ viability. When two copies of the 0.8 kb construct were introduced, however, $C h a^{11} / C h a^{13.3}$ adults were observed in three of the four independently transformed lines. Of these three lines, the percentage of $C h a^{11} / C h a^{153}$ adults in the progeny of $0.8 \mathrm{~kb}-\mathrm{ChAT}$ line 6 was comparable to that expected for complcte rescuc. In addition, many individuals developed to the pupal stage for the other two "partially" rescued lines $(0.8$ $\mathrm{kb}$-ChAT line 7 and line 10). We, thus, conclude that the $0.8 \mathrm{~kb}$ fragment has the ability to direct ChAT expression in appropriate neurons to rescue the lethality of nonconditional, as well as conditional Cha mutants. The more effective rescue rate in conditional $C h a^{t s 1}$ mutants may be due to a small amount of residual 

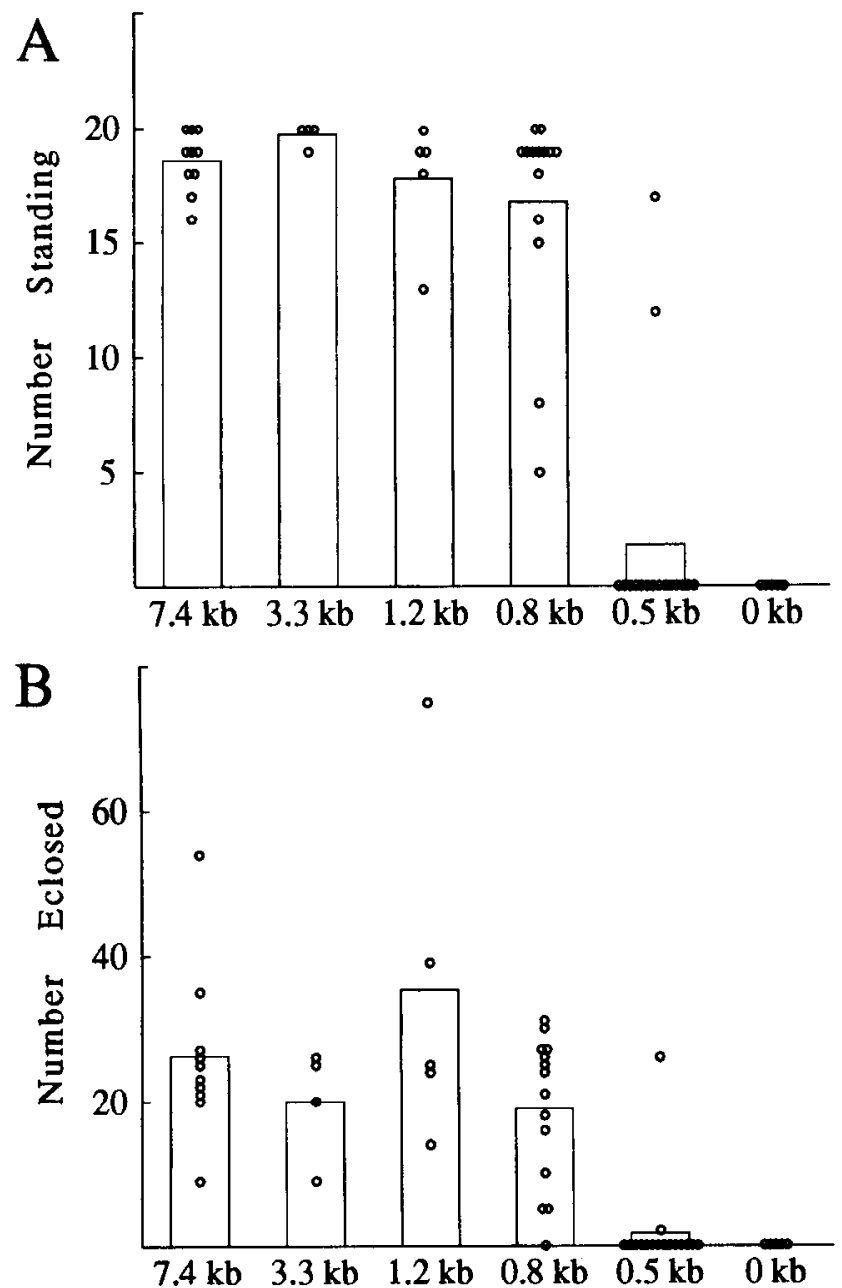

Figure 2. Rescue of $C h a^{t s 1}$ phenotypes with ChAT cDNA constructs. $A$. Adult paralysis: 20 flies, homozygous for $C h a^{t s}$ and carrying one copy of a transgene, were raised at $30^{\circ} \mathrm{C}$. After $4 \mathrm{~d}$ incubation, the number of standing flies for each independent line was counted (indicated by open circles). Each bar represents the averaged number for a group of transformants carrying the same construct. Under this condition all $C h a^{t s !}$ flies are paralyzed and lying on their backs or sides, while the wild-type flies are still fully active. $B$, Lethality: ten male transformants (homozygous for Chat and carrying one copy of a transgene) were crossed with $w$; Cha $a^{i s}$ females. They were kept at a permissive temperature $\left(22^{\circ} \mathrm{C}\right)$ for $2 \mathrm{~d}$, then transferred to a restrictive temperature $\left(3 \mathrm{I}-32^{\circ} \mathrm{C}\right)$ and allowed to lay eggs for $2 \mathrm{~d}$. Progeny were kept at the restrictive temperature and the number of eclosed adults was scored (indicated by open circles). Each bar represents the averaged number for a group of transformants carrying the same construct.

ChAT activity contributed by the mutant allele even at a restrictive temperature.

\section{Factor binding sites within the regulatory DNA necessary for} vital ChAT expression

The phenotypic rescue studies described above have identified the distal $0.3 \mathrm{~kb}$ of DNA in the $0.8 \mathrm{~kb}$ fragment as an important regulatory region for $\mathrm{ChAT}$ gene expression in mediating motor function(s) and viability. We have investigated the ability of this $0.3 \mathrm{~kb}$ of DNA to bind proteins that are presumed to be transcription factors for ChAT gene expression. The complete DNA sequence of the $0.8 \mathrm{~kb}$ fragment was determined and is shown in Figure $4 A$. There is no obvious TATA-box upstream of the transcriptional start site, and the upstream region is not partic-

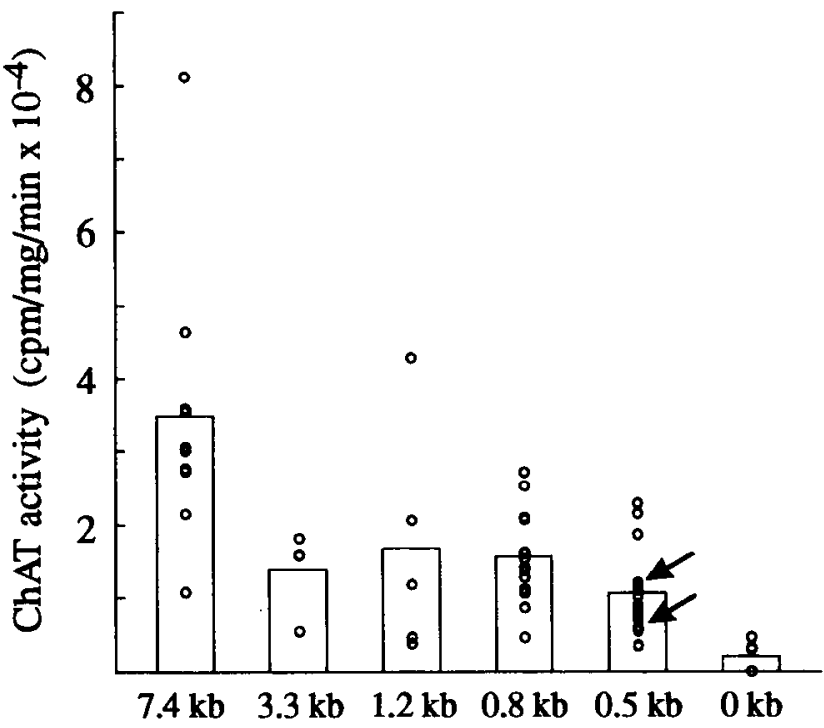

Figure 3. Transgenic ChAT activity. Females of each independent transformant line (homozygous for Cha $a^{(s)}$ and carrying one copy of a transgene) were homogenized and examined for ChAT activity (open circles). Before measuring the activity, the homogenates were incubated at $37^{\circ} \mathrm{C}$ for $30 \mathrm{~min}$ to inactivate the endogenous temperature-sensitive $C h a^{t c 1}$ enzyme activity (Greenspan, 1980; Salvaterra and McCaman, 1985). Arrows indicate ChAT activities of the two $0.5 \mathrm{~kb}$-ChAT lines that yielded progeny at the restrictive temperature (see Fig. 2). Each bar represents the average ChAT activity for a group of transformants carrying the same construct.

ularly CG rich. Absence of both TATA-box and CG-rich sequences is common to the promoters of several developmentally regulated Drosophila genes, such as engrailed (Soeller et al., 1988), Ultrabithorax (Biggin and Tijan, 1988), ecdysone-inducible gene: E74 (Thummel, 1989) and elav (Yao and White, 1994).

DNase I footprint analysis was done using the 316 bp of DNA ( -414 bp to $-99 \mathrm{bp}$, relative to the transcription start site) in

Table 1. Rescue of Cha lethal mutations

\begin{tabular}{|c|c|c|c|}
\hline Line & Linkage & \% Cha ${ }^{11 / C h a^{113}}$ & $\begin{array}{l}\% \\
\text { Expected }\end{array}$ \\
\hline \multicolumn{4}{|c|}{ Single copy of transgene } \\
\hline $7.4 \mathrm{~kb}-\mathrm{ChAT}-6$ & $\mathrm{X}$ & $26.7(27 / 101)^{*}$ & 20 \\
\hline $1.2 \mathrm{~kb}-\mathrm{ChAT}-1$ & $\mathrm{X}$ & $11.8(8 / 68)$ & 20 \\
\hline 7.4 kb-ChAT-4 & II & $26.8(33 / 123)$ & 25 \\
\hline $1.2 \mathrm{~kg}-\mathrm{ChAT}-2$ & II & $23.3(31 / 133)$ & 25 \\
\hline $1.2 \mathrm{~kb}-\mathrm{ChAT}-6$ & II & $24.0(24 / 100)$ & 25 \\
\hline $0.8 \mathrm{~kb}-\mathrm{Ch}$ AT- 6 & II & $9.4(5 / 53)$ & 25 \\
\hline $0.8 \mathrm{~kb}-\mathrm{ChAT}-7$ & II & $0(0 / 42)$ & 25 \\
\hline $0.8 \mathrm{~kb}-\mathrm{Ch} A \mathrm{~T}-9$ & II & $0(0 / 59)$ & 25 \\
\hline $0.8 \mathrm{~kb}-\mathrm{ChAT}-10$ & II & $0(0 / 38)$ & 25 \\
\hline \multicolumn{4}{|c|}{ Two copies of transgene } \\
\hline $0.8 \mathrm{~kb}-\mathrm{ChAT}-6$ & II & $34.9(59 / 169)$ & 33 \\
\hline $0.8 \mathrm{~kb}-\mathrm{ChAT}-7$ & II & $2.1(2 / 92)$ & 33 \\
\hline $0.8 \mathrm{~kb}-\mathrm{Ch}$ AT-9 & II & $0(0 / 111)$ & 33 \\
\hline $0.8 \mathrm{~kb}-\mathrm{ChAT}-10$ & II & $6.6(5 / 76)$ & 33 \\
\hline
\end{tabular}

The ability of various ChAT cDNA constructs to rescue the lethality of nonconditional Cha mutations was assayed by scoring the adult progeny of the crosses described in Materials and Methods.

* Number of flies with a $C h a^{\prime \prime} / C h a^{\prime \prime \prime}$ background/number of eclosed flies. 
A

\author{
$\rightarrow 0.8$ kb (-419) \\ AATGGCAAAA TGgCAAAAgC ACGCAATGAC AAAATgGgCG CAAAAAAtAg GCGCAAAAAA TAgTCGCACG \\ ACACACAAAC AAACAAACAA AGCAACCAAC ATTTGCAAAC CGACAGGTGA GAGCGAGCGg CCAAAAGGAA \\ ATTGATTTTC TCCGCACACT TCAAATAGAT TCTTATTAA ATGTGCTCAA CTGGGCGAGA GTAATGGGCC

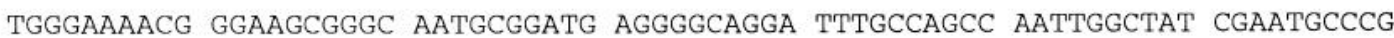 \\ $\rightarrow \mathbf{0 . 5} \mathbf{~ k b} \mathbf{( - 7 8 )}$ \\ GCGgAgGCGg CAgCGgCATC GgCAgATgTC CTGCGCCATg GAaggCTCAA GgTGCGgAgC TCCAGCCTTC \\ $\rightarrow$ mRNA \\ CAGGCTGAAT ACCTACTGCT GCTCGACGCT TTTTGCCAGC CGTCGCCAGA CAGAAGTTAC CTTTGCTCCT \\ GCCCGGACGA CTGAACGCAC GCTGCTGCTG TAACGCCGTA GTCGCCGTCC GTCGCCTGGA AAAAGAACTC \\ CCCGGAGCTA CATTGTATAG CCAGgAATAg AAAAAAAAAA AAAATAAATA AAAgAagTAT CATTTTTTGT

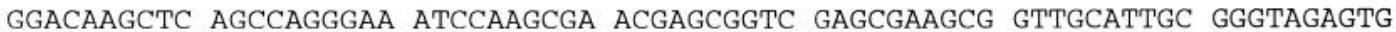 \\ TCAgTGTgTG TGTGTTTTGg CGTCGgTgTg AgCGTCTTGg CGATCGATTA GCGCGCGCTG CCCTTTTACA \\ TAATCGCAGC GAGAAAATC CGCGCGCTTT CGTGTGCTAT TTGCTTTTGg GTGATTTGgG CGATCATCCC \\ BamHI \\ $\rightarrow$ Protein \\ AAgCGACAAA GAAAAAgGg CCAAACCAAC CGGATCCGAA AGgAgCGAAC GTGGCGTCCA ACGAGGCCAG
}

B

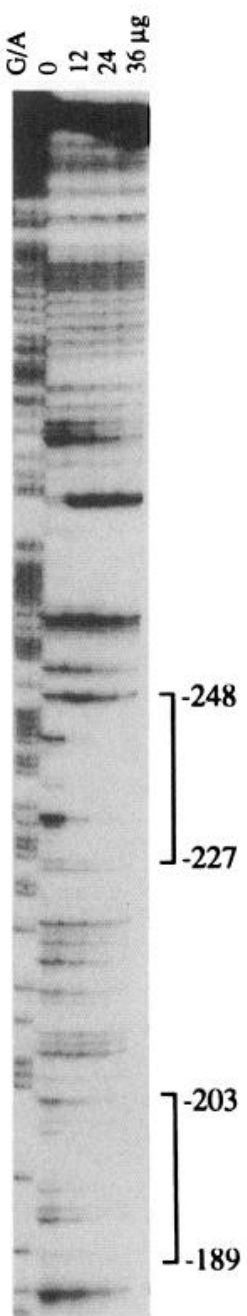

Figure 4. DNase I footprinting analysis of the proximal regulatory region of the ChAT gene. A. The sequence of the proximal regulatory region of the ChAT gene. The $5^{\prime}$ ends of the $0.8 \mathrm{~kb}$ and $0.5 \mathrm{~kb}$ fragments shown in Figure 1 correspond to positions $-419 \mathrm{bp}$ and $-78 \mathrm{bp}$, relative to the transcription start site. The junction between the upstream DNA and cDNA in Figure 1 corresponds to the BamHI site in the bottom line of this figure (underlined). The transcription and translation start sites are indicated as "mRNA" and "Protein," respectively. The DNase I-protected 22 bases are double underlined, and the octamer-like sequence is shown in bold letters (see text). B, The 316 bp fragment extending from -414 bp to $-99 \mathrm{bp}$, relative to the transcription start site, was ${ }^{32} \mathrm{P}$-labeled at the position of $-99 \mathrm{bp}$ and digested with DNase I in the presence of nuclear extracts derived from 10-22 hr embryos. The amount of extract is indicated at the top of each lane. The lane indicated by G/A contains MaxamGilbert purine cleavage fragments. The protection was most prominent at the sequence from -227 bp to -248 bp, and a relatively weak protection was observed at the sequence from $-189 \mathrm{bp}$ to $-203 \mathrm{bp}$.

the presence of a nuclear extract derived from 10-22 hr embryos. The most prominently protected site was observed for the sequence from -227 bp to $-248 \mathrm{bp}$, relative to the transcription start site (Fig. 4B). This site was also clearly protected when the other strand was labeled and tested (data not shown). The DNA sequence of this region is double underlined in Figure 4A. In the center of this protected 22 bp sequence we observed a sequence (ATTCAAAT) that differs by only a single base from the consensus octamer motif (ATGCAAAT), a transcriptional regulatory element found in the promoter and enhancer sequences of many genes (Falkner and Zachau, 1984; Bergman et al., 1984; Parslow et al., 1984; Ares et al., 1985; Mason et al., 1985; Mattaj et al., 1985; Carbon et al., 1987; LaBella et al., 1988). In addition to this 22 bp sequence, a weak protection was observed at the sequence from -189 bp to -203 bp (Fig. $4 B$ ), although this sequence was not evidently protected when the other strand was tested (data not shown).

Detection and characterization of binding factor(s) present in the embryonic nuclear extracts

In order to confirm the presence of binding factor(s) for the protected 22 bp sequence, we carried out electrophoretic mobility shift assays using the double-stranded 22-mer oligonucleotide as a radiolabeled probe (Fig. 5A, 22-mer). Nuclear extracts were prepared from 10-22 hr embryos and used as a source of putative transcription factor(s). In the presence of an excess amount $(2 \mu \mathrm{g} / 10 \mu \mathrm{l}$ reaction) of poly(dI-dC) and the absence of competitor oligonucleotides, binding factor(s) was apparent as the shift of one major band on the gel (Fig. $5 B$, lane 3 ; no competitor). Binding appears to be sequence specific for the 22-mer 
A

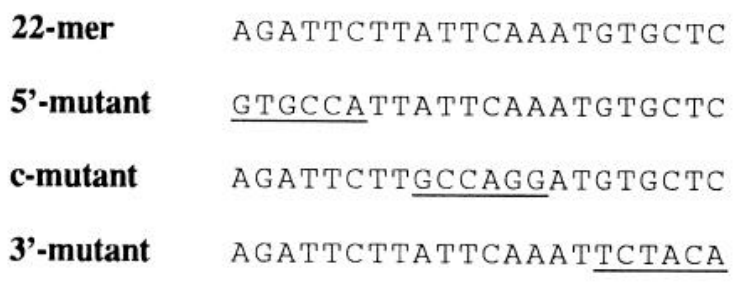

octamer-like

ATTCAAAT

octamer motif

ATGCAAAT

control

GATCCGGCAACGAAGGTACCATGG

B
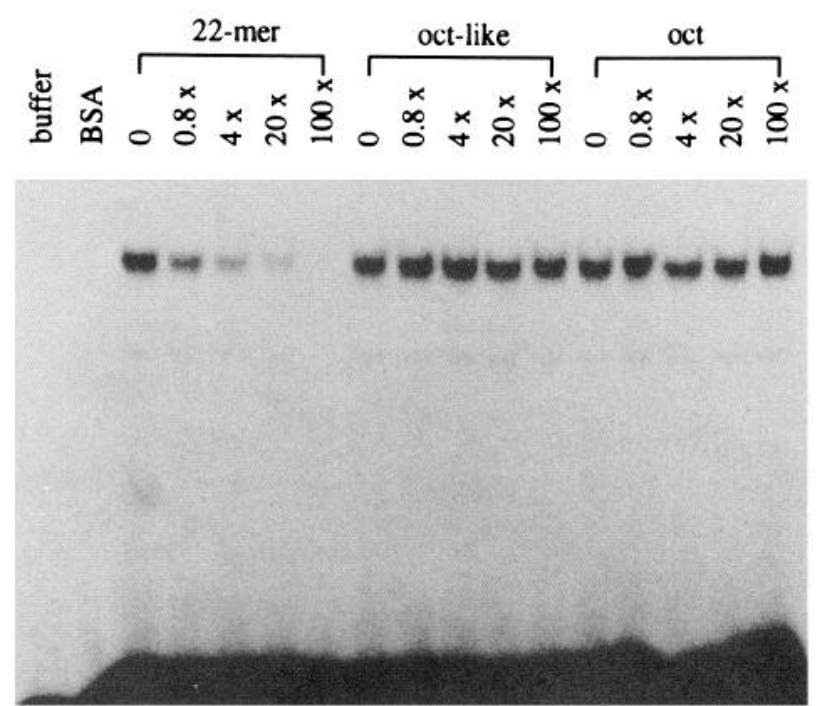

$\begin{array}{lllllllllllllllll}1 & 2 & 3 & 4 & 5 & 6 & 7 & 8 & 9 & 10 & 11 & 12 & 13 & 14 & 15 & 16 & 17\end{array}$
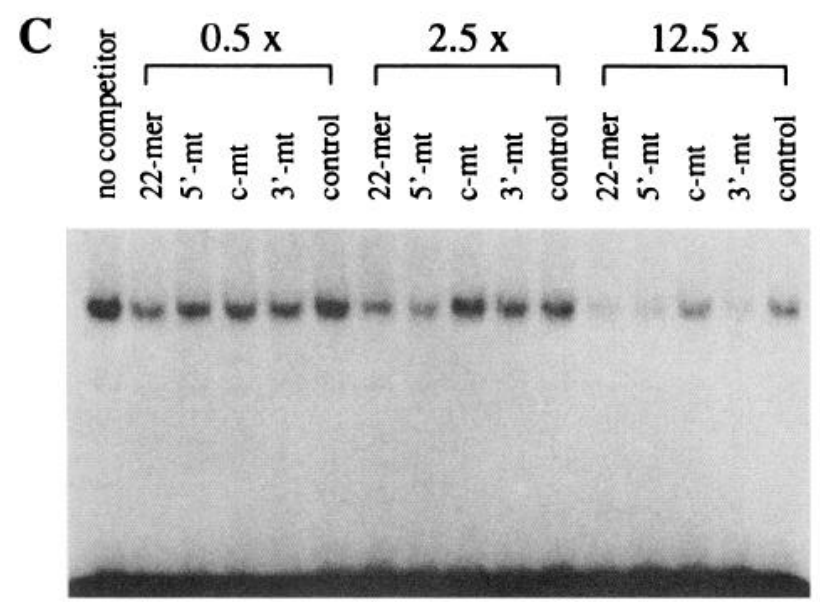

$\begin{array}{llllllllllllllll}1 & 2 & 3 & 4 & 5 & 6 & 7 & 8 & 9 & 10 & 11 & 12 & 13 & 14 & 15 & 16\end{array}$

Figure 5. Detection and characterization of binding factors by electrophoretic mobility shift assay. A. Oligonucleotides used in electrophoretic mobility shift assay. The 22 -mer corresponds to the DNase I-protected sequence (double-underlined in Fig. 4A). Sequences in $5^{\prime}-\mathrm{mt}$, c-mt, 3'-mt, octamer-like, and octamer motif are same as the original 22-mer except underlined bases. Control oligo is a control oligonucleotide with similar size (see Materials and Methods). B, The 22-mer was since the shifted band showed a dose-dependent decrease when increasing amounts of unlabeled 22-mer were added to the binding reaction mixture (Fig. 5B, lanes 4-7).

We have further defined the specificity of factor binding to the 22-mer by competition studies. The 22 -mer contains the octamer-like sequence in the middle (see Fig. $4 A$ ), but neither this endogenous octamer-like motif (oct-like) nor the consensus octamer motif (oct) showed an affinity high enough to compete for the binding of factor(s) with the 22-mer. A 100 -fold molar excess of oct-like or oct did not compete effectively with labeled 22-mer (Fig. 5B, lanes 8-12,13-17), and even a 2000-fold molar excess of oct-like or oct showed no ability to affect the interaction of putative transcription factor(s) and 22-mer (data not shown). Although the 8 bp of the octamer-like motif do not show a high affinity for the factors detected in Figure $5 B$ when tested alone, this sequence is important for the factors to form complexes with the 22-mer. We examined three oligonucleotides carrying clustered mutations in the 22 -mer sequence for their ability to compete with the original 22-mer. The mutations are located at the $5^{\prime}$ end, the center position or the $3^{\prime}$ end of the $22 \mathrm{bp}$ sequence. These oligonucleotides are designated as $5^{\prime}$-mutant, c-mutant and 3 '-mutant, respectively (altered sequences are underlined in Fig. $5 A$ ). The presence of a 12.5-fold excess of either 22-mer, $5^{\prime}$-mutant or $3^{\prime}$-mutant led to a decrease in the amount of labeled complex, while the c-mutant, which has nucleotide substitutions in six out of the eight positions in the octamer-like motif, did not compete with labeled 22-mer as effectively as other oligonucleotides (Fig. 5C, lanes 12-16). Base changes in the octamer-motif, thus, result in a decreased affinity of the c-mutant for factor(s) binding while base changes outside of the octamer-like sequence have little or no effect. These results indicate that the octamer-like sequence is essential for high affinity binding.

The molecular weight of the binding factor(s) was tentatively estimated by Southwestern blot analysis to be $130 \mathrm{kDa}$, as shown in Figure 6. Embryonic nuclear extract derived from 10$22 \mathrm{hr}$ embryos was subjected to SDS-polyacrylamide gel electrophoresis and the proteins were transferred to a nitrocellulose membrane that was subsequently probed with ${ }^{32} \mathrm{P}$-labeled concatenated 22-mer. In agreement with the result of Southwestern blot analysis, UV crosslinking experiments showed a specifically labeled band corresponding to a high molecular weight $(\mathrm{Mr}>$ $100,000)$ on an SDS-polyacrylamide gel (data not shown).

\section{Cloning of the putative ChAT gene transcription factor}

In order to identify the factor(s) detected in the DNA footprinting analysis, the electrophoretic mobility shift assay and the Southwestern blot analysis, we constructed and screened an embryonic cDNA expression library (derived from 10-22 hr embryos) with a ${ }^{32} \mathrm{P}$-labeled concatenated $22-$ mer probe. A positive phage was isolated and found to carry a $2.2 \mathrm{~kb}$ cDNA insert. The Bluescript phagemid containing the insert was excised from

$\leftarrow$

end labeled, and electrophoretic mobility shift assay was carried out using embryo nuclear extracts derived from 10-22 hr embryos. Lane 1 , no extract, lane 2 , no extract with BSA $(10 \mu \mathrm{g})$; lanes $3-17$, in the presence of unlabeled 22-mer, octamer-like, or octamer motif as a competitor at indicated molar excess of the labeled probe. $C$, The effect of clustered point mutations in 22-mer on the binding ability to the factor. Lane 1, no competitor; lanes 2-16, in the presence of 22-mer, $5^{\prime}$-mutant (5'-mt), c-mutant (c-mt), 3'-mutant (3'-mt), or control oligonucleotide (control) as a competitor at indicated molar excess of labeled probe. 


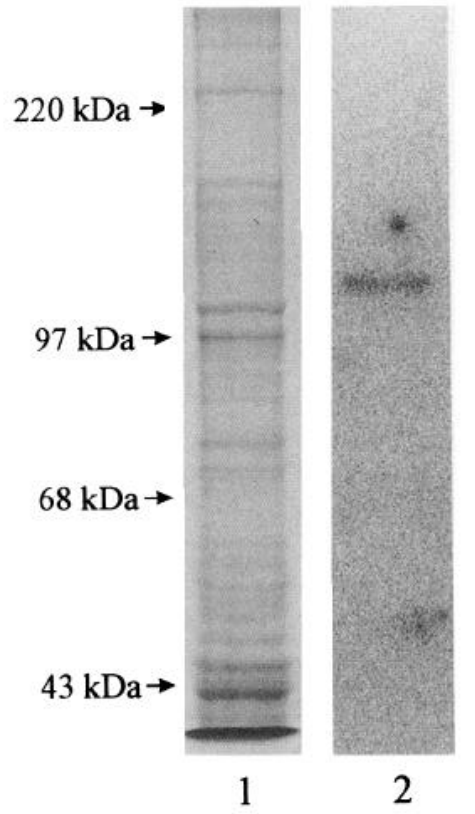

Figure 6. Estimation of molecular weight of the binding factor by Southwestern blot analysis. Embryo nuclear extract derived from $10-$ $22 \mathrm{hr}$ embryos was subjected to SDS-PAGE, and protein bands were transferred to a nitrocellulose membrane. The membrane was incubated with ${ }^{32} \mathrm{P}$-labeled concatenated 22 -mer (Fig. $5 A$ ), followed by autoradiography. Lane I, Coomasie brilliant blue staining; lane 2, Southwestern blot. The positions of the molecular weight standards are marked on the left. The sequence specific binding protein appeared as a polypeptide of $\sim 130 \mathrm{kDa}$.

the $\lambda$ - ZAP vector and recircularized in vivo (designated as clone 9-A1). Sequence-specific DNA binding activity of the $\beta$-galactosidase fusion protein expressed by $9-\mathrm{Al}$ was confirmed by examining $E$. coli extracts prepared from a 9-A1 culture. Southwestern blot analysis showed that the extracts prepared from IPTG-induced cultures contained a specific binding factor with a molecular weight of $\sim 50 \mathrm{kDa}$ (Fig. $7 A$ : 1-4 hr incubation in the presence of IPTG), while no binding activity was detected in the control extracts (no incubation in the presence of IPTG or $4 \mathrm{hr}$ incubation in the absence of IPTG). The binding specificity of the fusion protein expressed by $9-\mathrm{A} 1$ was further ana- lyzed by electrophoretic mobility shift assay (Fig. 7B). The expressed protein showed the same characteristic pattern as was seen for factor(s) present in the embryonic extract. The binding of the expressed protein to radiolabeled 22-mer was competed well by unlabeled 22 -mer, $5^{\prime}$-mutant, and $3^{\prime}$-mutant, but not by the octamer-like motif, the consensus octamer motif, and c-mutant that carries mutations in the octamer-like sequence.

The 9-A1 clone was sequenced and was found to be a part of dPOU-19/pdm-1 (Billin et al., 1991; Dick et al., 1991; Lloyd and Sakonju, 1991), which is one of the Drosophila POU domain genes identified by sequence similarity to other POU domain genes. Our clone starts with the nucleotide position 627 of the $d P O U-19 / p d m-I$ clone isolated by Billin et al. (1991) and shows an identical protein coding sequence with it. The 9-A1 product, thus, does not contain the $\mathrm{N}$-terminal 138 amino acids of dPOU-19/pdm-1 but does contain a POU-specific domain and a POU-homeodomain. There are at least two base differences between sequences in the $3^{\prime}$ untranslated region of the $\mathrm{dPOU}$ $19 / p d m-1$ clone and the 9-A 1 clone. Nucleotides 2269 and 2676 of the $d P O U-19 / p d m-1$ clone (Billin et al., 1991) are $\mathrm{C}$ and $\mathrm{G}$, while corresponding nucleotides are both $\mathrm{T}$ in the 9-Al clone.

\section{Discussion}

In previous studies we have shown that Drosophila ChAT gene expression is regulated by the combined action of multiple regulatory elements located within $7.4 \mathrm{~kb}$ of the $5^{\prime}$ flanking region (Kitamoto et al., 1992; Kitamoto and Salvaterra, 1993). Smaller amounts of $5^{\prime}$ flanking sequence result in a more restricted expression pattern of reporter gene expression in most cases. In this study we have found that as little as $0.8 \mathrm{~kb}$ of DNA, including 419 bp of $5^{\prime}$ and $391 \mathrm{bp}$ of first exon sequence, has the ability to direct ChAT expression in an appropriate manner to restore viability of lethal Cha mutants. Phenotypic rescue does not depend solely on the amount of ChAT enzyme activity in the transformants, as evidenced by the overlap of activity levels in the rescued $0.8 \mathrm{~kb}$ lines and the unrescued $0.5 \mathrm{~kb}$ lines. The $0.8 \mathrm{~kb}$ of DNA, but not $0.5 \mathrm{~kb}$, should, thus, regulate ChAT expression in critical cholinergic neuronal population(s) that are necessary for viability. The distal regulatory elements, located upstream of $0.8 \mathrm{~kb}$, can modify ChAT expression in both a qualitative and quantitative manner, but are not essential for restoring
$\mathbf{A}$

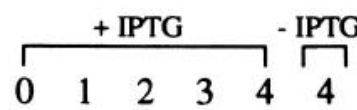

(hr)
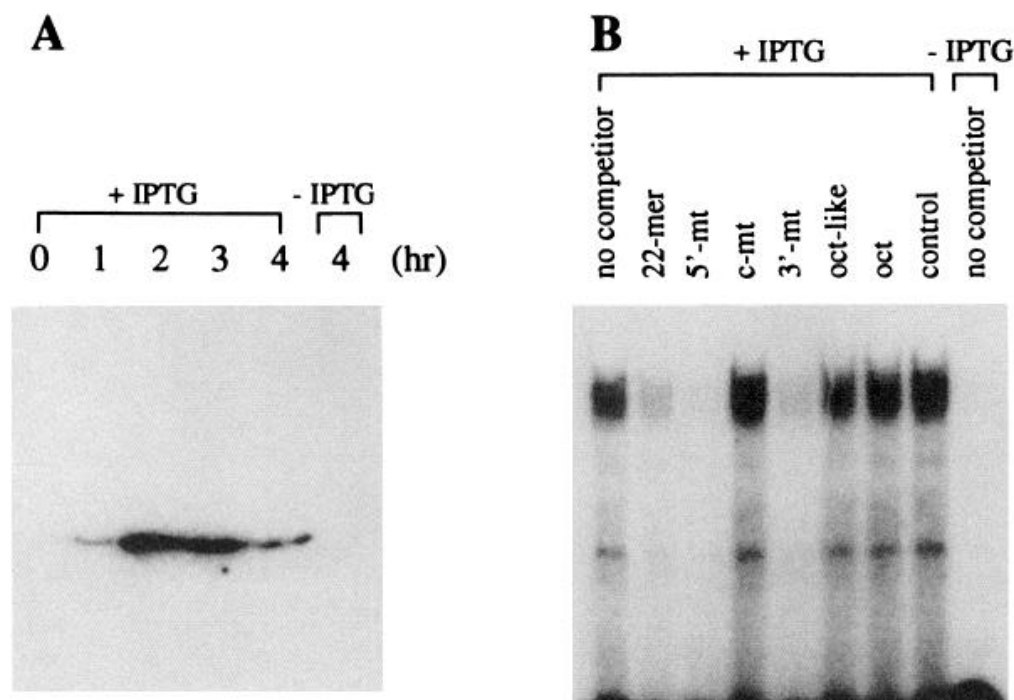

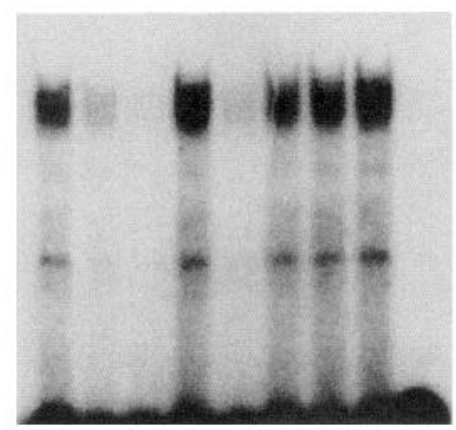

Figure 7. Detection and characterization of the 9-Al product. $A$, Southwestern blot analysis. Lysates of bacteria carrying the 9-Al clone were prepared after incubation for indicated time at $37^{\circ} \mathrm{C}$ in the presence or absence of $1 \mathrm{~mm}$ IPTG. They were subjected to Southwestern blot analysis using ${ }^{32} \mathrm{P}$ labeled concatenated 22-mer as a probe. $B$, Electrophoretic mobility shift assay. The 22-mer was end labeled, and electrophoretic mobility shift assay was carried out using crude extracts prepared from 9-A1 cultures. Indicated oligonucleotides were added in reactions at 12.5-fold (for 22-mer, 5'-mutant, c-mutant, and 3'-mutant) or 33fold (for octamer-like, octamer, and control oligonucleotide) molar excess of the labeled 22-mer. 
motor control and/or survival to Cha mutant animals. Perhaps the more distal regulatory elements are necessary to rescue other cholinergic neurons that are essential for more subtle putative cholinergic functions, such as courtship or visually mediated behaviors (Greenspan, 1980).

The Drosophila ChAT gene appears to use a strategy of positive regulation as the major mechanism to accomplish specific expression in most cholinergic neurons since the $0.8 \mathrm{~kb}$ DNA, when fused to the wild-type ChAT cDNA, has ability to rescue Cha mutant phenotypes. In addition, immunocytochemical studies of $0.8 \mathrm{~kb}$ transformants with a nonconditional Cha lethal background reveal that ChAT expression is confined to only restricted regions of the nervous system ( $\mathrm{K}$. Yasuyama et al., in preparation) when compared to the normal ChAT expression pattern. Small promoter-containing fragments necessary and possibly sufficient for neural-specific expression have also been found in the rat synapsin I gene (Sauerwald et al., 1990), the rat GAP-43 gene (Nedivi et al., 1992), and the Drosophila elav gene (Yao and White, 1994). This type of regulation for neural-specific expression is in contrast to several mammalian neural-specific genes that use negative regulation as a major mechanism (Mandel and McKinnon, 1993). For instance, removal of silencer-like sequences derepresses promoter activity of the type-II sodium channel gene and the SCG10 gene in cell lines and tissues that do not ordinarily express the endogenous genes (Maue et al., 1990; Mori et al., 1990; Wuenschell et al., 1990; Kraner et al., 1992). Some evidence is also available for the importance of negative regulation for human ChAT gene expression (Li et al., 1993).

The distal $0.3 \mathrm{~kb}$ of the $0.8 \mathrm{~kb}$ DNA necessary for vital expression of ChAT contains a DNase-protected site that spans 22 bp of DNA. Although we don't yet have direct evidence that this 22 bp sequence is the relevant cis-acting "cholinergic" element, the sequence is likely to participate in the phenotypic rescue of Cha mutants, since the sequence shows the most prominent footprint in the $0.3 \mathrm{~kb}$ DNA and is the target of specific binding factors present in nuclear extracts.

Furthermore, this 22 bp sequence is highly conserved in the proximal regulatory region of the ChAT gene recently isolated from the evolutionarily diverged species Drosophila virilis (S. Liang and P. M. Salvaterra, unpublished data), reinforcing its functional importance. It includes the octamer-like motif, which is essential for high affinity binding of factor(s), and has only a single base difference from the consensus octamer motif (Falkner and Zachau, 1984; Parslow et al., 1984). The consensus octamer motif is recognized by octamer binding proteins that belong to a versatile family of transcription factors referred to as POU domain proteins. The POU domain proteins include a number of proteins that can regulate gene expression in both a positive and negative manner and can be cell-type specific or more general (for review, see Wegner et al., 1993). Recent studies have defined six classes of POU domain proteins (He et al., 1989) and have even identified members that can recognize a surprising number of degenerate sequences (Baumruker et al., 1988).

In Drosophila, four genes $(C f I-a, d P O U-19 / p d m-1, d P O U$ $28 / p d m-2$ and $I-P O U$ ) encoding POU domain proteins have been identified (Johnson and Hirsh, 1990; Billin et al., 1991; Dick et al., 1991; Lloyd and Sakonju, 1991; Treacy et al., 1991). Among these, the $C f I-a$ gene product binds to a distal enhancer element of the Dopa decarboxylase gene $(D d c)$ and has been proposed to positively regulate neural-specific $D d c$ expression (Johnson and Hirsh, 1990). Neuronal $D d c$ expression is a key event in the specification of dopaminergic and serotonergic neurotransmitter phenotypes. The $\mathrm{Cf1}$-a binding site contains the sequence (AATCAAAT) that has only a single base difference from the ChAT octamer-like sequence and differs in two positions from the consensus octamer motif (Johnson et al., 1989). In vertebrate pituitary gland, the specification of three specific types of secretory cells also depends critically on a mechanism involving POU transcription factors, Pit-1 (Li et al., 1990; Simmons et al., 1990). It is possible that other genes encoding neurotransmitter synthesizing enzymes, or neuropeptides, may also utilize the POU family of transcription factors to result in cell-type-specific expression patterns.

Using the 22-mer sequence (containing the octamer-like motif) as a probe, we have isolated a clone corresponding to a part of $d P O U-19 / p d m-1$. The $d P O U-19 / p d m-1$ and $d P O U-28 / p d m-2$ genes were isolated solely by their sequence similarity to other POU domain genes (Billin et al., 1991; Dick et al., 1991; Lloyd and Sakonju, 1991). Although several observations implicate the involvement of dPOU-19/pdm-1 and dPOU-28/pdm-2 in specification of specific neuronal cell fates (Billin et al., 1991; Dick et al., 1991; Lloyd and Sakonju, 1991; Yang et al., 1993), the identity of their specific binding sites and target genes remains unknown. Our results have shown that a $d P O U-19 / \mathrm{pdm}-1$ gene product binds to the 22-mer sequence in vitro, suggesting its participation in regulating ChAT expression. None of the characterized forms of dPOU-19/pdm-1 are likely to be the factor(s) that binds to the 22 bp sequence in vivo, since the ChAT gene transcription factor has a larger molecular size. The largest open reading frame described so far for cloned $\mathrm{dPOU}-19 / \mathrm{pdm}-1$ cDNA contains only 1806 bp and could encode only a $65 \mathrm{kDa}$ protein (Billin et al., 1991; Dick et al., 1991; Lloyd and Sakonju, 1991). The molecular weight we observe for the 22-mer binding factor in embryonic extracts appears to be $130 \mathrm{kDa}$ in Southwestern analysis. In spite of this discrepancy in molecular size, we believe that the binding factor(s) we detected in embryonic extracts is related to dPOU-19/pdm-1 for several reasons. They both exhibit a high affinity for the DNase-protected 22-mer. 'The embryo extract factor and our 9-A1, a partial $d P O U-19 / \mathrm{pdm}-1$ clone, show an identical specificity of competition for the mutated 22-mer. It is possible that the difference in apparent molecular size can be attributed to posttranslational modification(s) of dPOU-19/pdm-1, or, alternatively, that the larger factor we detect corresponds to another form of dPOU-19/pdm-1. The dPOU-19/pdm-1 cDNA clones isolated to date are about $2.8 \mathrm{~kb}$ or shorter, while Northern blot analysis reveals the presence of larger transcripts ranging in size up to $\sim 4.9 \mathrm{~kb}$ (Billin et al., 1991; Lloyd and Sakonju, 1991). The $d P O U-19 / p d m-1$ cDNA clones isolated so far, including our 9-Al clone, may, thus, correspond to only the shorter transcripts.

$d P O U-19 / p d m-1$ is expressed as two stripes in the presumptive abdominal region during the blastoderm stage, followed by 13 stripes in the germ band extended stage. In later stage embryos, $d P O U-19 / \mathrm{pdm}-1$ is expressed in selected neuroblasts and neurons in the central and peripheral nervous systems (Dick et al., 1991; Lloyd and Sakonju, 1991). The temporal and spatial patterns of ChAT gene expression overlapped but do not completely coincide with those of $d P O U-19 / p d m-1$ (Carbini et al., 1990; Kitamoto and Salvaterra, 1993). For instance, ChAT mRNA can first be detected at stage 10 or 11 (Carbini et al., 1990) while $d P O U-19 / p d m-1$ transcripts are observed at stage 5 . There may be an as yet unknown mechanism regulating the 
activity of $d P O U-19 / p d m-1$ so that ChAT transcription is turned on at the right time and the right place. A member of Drosophila POU-domain protein family, I-POU, which lacks the ability to bind DNA, can dimerize with $\mathrm{Cfl}-\mathrm{a}$ and inhibit its binding to the $D d c$ distal enhancer in vitro has been described (Treacy et al., 1991). A comparable mechanism may also operate at the early stages of ChAT expression.

Our results indicate the biological importance of a $0.3 \mathrm{~kb}$ sequence of $5^{\prime}$ flanking DNA for regulation of ChAT gene expression in essential cholinergic neurons. We propose that the 22 bp sequence containing an octamer-like motif is an essential part of the regulatory expression of the ChAT gene. We are now constructing transgenic animals with specific point mutations to test this hypothesis in vivo. It should also be possible to obtain support for this proposal by measuring ChAT expression in $d P O U-19 / p d m-1$ mutants. Unfortunately, none have yet been reported.

\section{References}

Ares JM, Mangin M, Weiner AM (1985) Orientation dependent transcriptional activation of a human U2 snRNA gene. Mol Cell Biol $5: 1560-1570$.

Baumruker T, Sturm R, Herr W (1988) OBP100 binds remarkably degencratc Octamer motif through spccific intcractions with flanking sequences. Genes Dev 2:1400-1413.

Bergman Y, Rice D, Grosscheld R, Baltimore D (1984) Two regulatory elements for immunoglobulin $\mathrm{k}$ light chain gene expression. Proc Natl Acad Sci USA 81:7041-7045.

Biggin MD, Tijian R (1988) Transcription factors that activate the U1trabithorax promoter in developmentally staged extracts. Cell 53: 699-711.

Billin AN, Cockerill KA, Poole SJ (1991) Isolation of a family of Drosophila POU domain genes expressed in early development. Mech Dev 34:75-84.

Bowtell DD, Lila T, Michael M, Hackett D, Rubin GM (1991) Analysis of the enhancer element that controls expression of sevenless in the developing Drosophila eye. Proc Natl Acad Sci USA 88:6853-6857.

Campos-Ortega JA, Jan YN (1991) Genetic and molecular bases of neurogenesis in Drosophila melanogaster. Annu Rev Neurosci 14: $399-420$.

Carbini LA, Munoz-Maines VJ, Salvaterra PM (1990) Developmental expression of choline acetyltransferase mRNA in Drosophila. Neurochem Res 15:1089-1096.

Carbon P, Murgo S, Ebel JP, Krol A, Tebb G, Mattaj IW (1987) A common octamer motif binding protein is involved in the transcription of U6 snRNA by RNA polymerase III and U2 snRNA by RNA polymerase II. Cell 51:71-79.

Chirgwin JM, Przybyla AE, MacDonald RJ, Rutter WJ (1979) Isolation of biologically active ribonucleic acid from sources enriched in ribonuclease. Biochemistry 18:5294-5299.

Chodosh, A (1988) Mobility shift DNA-binding assay using gel electrophoresis. In: Current protocols in molecular biology (Ausubel FM, Brent R, Kingston RE, Moore DD, Seidman JG, Smith JA, Struhl K, eds), pp 12.2.1-12.2.10. New York: Greene/Wiley.

Dick T, Yang X, Yeo S, Chia W (1991) Two closely linked Drosophila POU domain genes are expressed in neuroblasts and sensory elements. Proc Natl Acad Sci USA 88:645-7649.

Falkner FG, Zachau HG (1984) Correct transcription of an immunoglobulin $\kappa$ gene requires an upstream fragment containing conserved sequence elements. Nature 310:71-74.

Goodman CS, Doe CQ (1993) Embryonic development of the Drosophila CNS. In: The development of Drosophila melanogaster (Bate M, Arias, AM, eds), pp 1131-1206. Cold Spring Harbor, NY: Cold Spring Harbor Laboratory.

Gorczyca MG, Hall JC (1984) Identification of a cholinergic synapse in the giant fiber pathway of Drosophila using conditional mutations of acetylcholine synthesis. J Neurogen 1:289-313.

Greenspan RJ (1980) Mutations of choline acetyltransferase and associated neural defects in Drosophila melanogaster. J Comp Physiol 137:83-92.
Hall JC, Greenspan RJ, Kankel DR (1979) Soc Neurosci Symp 4:142.

He X, Treacy MN, Simmons DM, Ingraham HA, Swanson LW, Rosenfeld MG (1989) Expression of a large family of POU-domain regulatory genes in mammalian brain development. Nature 340:35-42.

Heberlein U, Tjian R (1988) Temporal pattern of alcohol dehydrogenase gene transcription reproduced by Drosophila stage-specific embryonic extracts. Nature 331:410-415.

Itoh N, Slemmon JR, Hawke DH, Williamson R, Morita E, Itakura K, Roberts E, Shively JE, Crawford GD, Salvaterra PM (1986) Cloning of Drosophila choline acetyltransferase cDNA. Proc Natl Acad Sci USA 83:4081-4085.

Jan YN, Jan LY (1993) The peripheral nervous system. In: The development of Drosophila melanogaster (Bate M, Arias AM, eds), pp 1207-1244. Cold Spring Harbor, NY: Cold Spring Harbor Laboratory.

Johnson WA, Hirsh J (1990) Binding of a Drosophila POU-domain protein to a sequence element regulating gene expression in specific dopaminergic neurons. Nature 343:467-470.

Johnson WA, McCormick CA, Bray SJ, Hirsh J (1989) A neuronspecific enhancer of the Drosophila Dopa decarboxylase gene. Genes Dev 3:676-686.

Kitamoto T, Salvaterra PM (1993) Developmental regulatory elements in the 5' flanking DNA of the Drosophila choline acetyltransferase gene. Rouxs Arch Dev Biol 202:159-169.

Kilamoto T, Ikeda K, Salvaterra PM (1992) Analysis of cis-regulatory elements in the $5^{\prime}$ flanking region of the Drosophila melanogaster choline acetyltransferase gene. J Neurosci 12:1628-1639.

Kraner S, Chong JA, Tsay H-J, Mandel G (1992) Silenceing the type II sodium channel gene: a model for neural-specific gene regulation. Neuron 9:37-44.

LaBella F, Sive HL, Roeder RG, Heintz N (1988) Cell-cycle regulation of a human histone $\mathrm{H} 2 \mathrm{~b}$ gene is mediated by the $\mathrm{H} 2 \mathrm{~b}$ subtype-specific consensus element. Genes Dev 2:32-39.

Li S, Crenshaw EB, Rawson EJ, Simmons DM, Swanson LW, Rosenfeld MG (1990) Dwarf Locus Mutants Lacking three pituitary cell types result from mutations in the POU-domain gene Pit- 1 . Nature 347:528-533.

Li YP, Baskin F, Davis R, Hersh LB (1993) Cholinergic neuron-specific expression of the human choline acetyltransferase gene is controlled by silencer elements. J Neurochem 61:748-751.

Lindsley D, Zimm G (1992) The genome of Drosophila melanogaster. San Diego: Academic.

Lloyd A, Sakonju S (1991) Characterization of two Drosophila POU domain genes related to oct-I and oct-2 and the regulation of their expression pattern. Mech Dev 36:87-102

Mandel G, McKinnon D (1993) Molecular basis of neural-specific gene expression. Annu Rev Neurosei 16:323-345.

Mason JO, Williams GT, Neuberger MS (1985) Transcription cell type specificity is conferred by an immunoglobulin $V_{11}$ promoter that includes a functional consensus sequence. Cell 41:479-487.

Mattaj IW, Lienhard S, Jiricny J, DeRobertis EM (1985) An enhancer like sequence within the Xenopus U2 gene promoter facilitates the formation of stable transcription complexes. Nature 316:163-167.

Maue RA, Kraner SD, Goodman RH, Mandel G (1990) Neuron-specific expression of the rat brain type II sodium channel gene is directed by upstream regulatory elements. Neuron 4:223-231.

Mori N, Stein R, Sigmund O, Anderson DJ (1990) A cell type-preferred silencer element that controls the neural-specific expression of the SCG10 gene. Neuron 4:583-594.

Nedivi E, Basi GS, Akey IV, Skene JHP (1992) A neural-specific GAP43 core promoter located between unusual DNA elements that interact to regulate its activity. J Neurosci 12:691-704.

Parslow TG, Blair DL, Murphy WJ, Granner DK (1984) Structure of the 5 ' ends of immunoglobulin genes: a novel conserved sequence. Proc Natl Acad Sci USA 81:2650-2654.

Rubin GM, Spradling AC (1982) Genetic transformation of Drosophila with transposable element vectors. Science 218:348-353.

Salvaterra PM, McCaman RE (1985) Choline acetyltransferase and acetylcholine levels in Drosophila melanogaster: a study using two temperature-sensitive mutants. J Neurosci 5:903-910.

Sambrook J, Fritsch EF, Maniatis T (1989) Molecular cloning: a laboratory manual, $2 \mathrm{~d}$ ed. Cold Spring Harbor, NY: Cold Spring Harbor Laboratory. 
Sanger F, Nicklen S, Coulson AR (1977) DNA sequencing with chainterminating inhibitors. Proc Natl Acad Sci USA 74:5463-5467.

Sauerwald A, Hoesche C, Oschwald R, Kilimann MW (1990) The 5'flanking region of the synspsin I gene. J Biol Chem 265:1492314937.

Schneider LE, Roberts MS, Taghert PH (1993) Cell type-specific transcriptional regulation of the Drosophila FMRMamide neuropeptide gene. Neuron 10:279-291.

Simmons DM, Voss JW, Ingraham HA, Holloway JM, Broide RS, Rosenfeld MG, Swanson LW (1990) Pituitary cell phenotypes involve cell-specific Pit-1 mRNA translation and synergistic interactions with other classes of transcription factors. Genes Dev 4:695-711.

Soeller WC, Poole SJ, Kornberg T (1988) In vitro transcription of the Drosophila engrailed gene. Genes Dev 2:68-81.

Sugihara H, Andrisani V, Salvaterra, PM (1991) Genomic organization of Drosophila choline acetyltransferase gene. J Neurochem 57:16361642.

Thummel CS (1989) The Drosophila E74 promoter contains essential sequences downstream from the start site of transcription. Genes Dev $3: 782-792$.
Thummel CS, Boulet AM. Lipshitz HD (1988) Vectors for Drosophila P-element-mediated transformation and tissue culture transfection. Gene 74:445-456.

Treacy MN, He X, Rosenfeld MG (1991) I-POU: a POU domain pro tein that inhibits neuron-specific gene activation. Nature 350:577584

Wegner M, Drolet DW, Rosenfeld MG (1993) POU-domain proteins: structure and function of developmental regulators. Curr Opin Cell Biol 5:488-498.

Wuenschell CW, Mori N, Anderson DJ (1990) Analysis of SCG10 gene expression in transgenic mice reveals that neural specificity is achieved through selective derepression. Neuron 4:595-602.

Yang X, Yeo S, Dick T, Chia W (1993) The role of a Drosophila POU homeo domain gene in the specification of neuronal precursor cell identity in the developing embryonic central nervous system. Genes Dev 7:504-516.

Yao K-M, White K (1994) Neural specificity of elav expression: defining a Drosophila promoter for directing expression to the nervous system. J Neurochem 63:41-51. 